\title{
Predominant spirometric pattern in patients with chronic airflow obstruction due to pulmonary Tuberculosis sequelae
}

\begin{abstract}
Objective: The objective of this study is to determine the predominant spirometric pattern in patients with chronic airflow obstruction (CAO) due to pulmonary tuberculosis (PTB) sequelae (CAO-PTB) in family health center of La Florida, Talca.

Methods: Descriptive study of 17 patients ( 5 men, 12 women), with a mean age \pm SD of $72 \cdot 8 \pm 8 \cdot 4$ years, with a CAO-PTB diagnostic, who underwent a basal and post bronchodilator spirometry. The measured variables were: basal and post bronchodilator FEV1/FVC, FEV1, FVC, FEF 25-75\%, and change in FEV1 and FVC, measured in percentage and $\mathrm{ml}$. The statistical analysis was made using the software SPSS, version 23.

Results: Of the 17 evaluated patients, 13 showed an obstructive spirometric pattern $(76 \cdot 5 \%), 3$ a normal spirometric pattern $(17 \cdot 6 \%)$ and 1 a restrictive spirometric pattern $(5 \cdot 9 \%)$. Of the 13 patients with obstructive spirometric pattern, 7 presented a normal FVC $(53 \cdot 9 \%)$, and 6 a diminished FVC $(46 \cdot 1 \%)$. Regarding the changes post bronchodilator, 6 patients showed significant changes $(35 \cdot 3 \%)$, which were all obstructive, and 11 patients had no significant changes $(64 \cdot 7 \%)$, being 7 obstructive, 3 normal, and 1 restrictive.
\end{abstract}

Conclusion: The predominant spirometric pattern of the evaluated patients with CAO-PTB, in the family health center La Florida, Talca, was the obstructive with normal FVC, and no significant changes post bronchodilator were found.
Volume 4 Issue I - 2019

\author{
Jiménez J, Latrach A, Martínez R, Navarrete \\ C, Ortiz M \\ Family Health Center La Florida, Talca, Chile
}

Correspondence: Klgo Jaime Jimenez S, Family Health Center La Florida,Talca, Chile, Email jaime_jimenez25@hotmail.com

Received: January 05, 2019 | Published: February 20, 2019

Keywords: chronic airflow obstruction, pulmonary tuberculosis, spirometric pattern

\section{Introduction}

The chronic airway obstruction (CAO) constitutes a group of obstructive diseases that have in common the narrowing of the airways, with a consequent airflow resistance and respiratory work increase. These diseases are: COPD, Irreversible Asthma, Bronchiectasis, Pneumoconiosis, Cystic Fibrosis, Obliterating Bronchiolitis, and the Pulmonary Tuberculosis (PTB) sequelae. ${ }^{1}$

Pulmonary Tuberculosis is characterized by the formation of granulomas and spots of caseous necrosis, which produce destructive effects in the Pulmonary parenchyma, affecting the apical lobes and generating sequelae after the bactereological cure of the disease. ${ }^{2}$ It has been described that nearly $70 \%$ of the ill people that cure and get pulmonary tuberculosis sequelae may develop, with the years, a CAO which may lead to a respiratory insufficiency and cor pulmonale. ${ }^{3,4}$ The ventilatory limitation that these patients develop has a restrictive component given the fibrous lesions and scars of the pulmonary parenchyma where the wound occurred, and an obstructive component due to the compensatory hyperinflation of the remaining healthy lung. ${ }^{5}$ In theory, this would correspond to an obstructive spirometric pattern with diminished FVC. This pattern is supported by the few studies about this topic, in which the authors agree that the predominant spirometric pattern in these patients would effectively be the obstructive one, and consider it similar to the COPD. ${ }^{6}$ This is why the objective of this research is to determine the predominant spirometric patter in the patients with chronic airflow obstruction (CAO) due to pulmonary tuberculosis (PTB) sequelae (CAO-PTB) in our family health center, and compare the results with the precedent studies, or to determine a different spirometric pattern to the one prescribed by the existent literature, so as to contribute to the general knowledge of this little studied group of patients.

\section{Methods}

The protocol of the study was approved by the health service scientific ethics committee of the Maule Region, and every involved subject signed a consent letter. Descriptive study of 17 patients (5 men, 12 women), with a mean age \pm SD of $72 \cdot 8 \pm 8 \cdot 4$ years with a CAO-PTB diagnostic. Inclusion criteria were: patients over 50 years old with a medical diagnostic of CAO-PTB. Exclusion criteria were: patients with additional chronic respiratory diseases such as: COPD, Asthma, Interstitial lung diseases (ILD), including connective tissue diseases (CTD) compromising the lung and CAO produced by a cause different from tuberculosis. In addition, patients that presented contraindications regarding spirometry were excluded, such the ones suffering from: unstable cardiovascular status, recent myocardial infarction (within 1 month) or pulmonary embolism, uncontrolled hypertension or history of recent haemorrhagic cerebrovascular event, endocranean hypertension syndrome, recent pneumothorax (within 1 month), thoracic, abdominal or cerebral aneurysms, recent thoracic, abdominal or eye surgery, haemoptysis of unknown origin, thoracic pain of unknown origin and unlikely to be able to comply with instructions. ${ }^{7-9}$

All 17 selected patients were assessed in basal and post bronchodilator spirometry, following the standardized criteria of the European Respiratory Society (ERS). ${ }^{10,11}$ The spirometer used was the Vitalograph Model 6800, previously calibrated with a 3 litter calibrated syringe. Each patient got, at least, 3 acceptable and repeatable curves of forced expiration and the best values of FVC and 
FEV1 were selected. ${ }^{12,13}$ The dose and the bronchodilator used for the post test was $400 \mu \mathrm{g}$ of salbutamol through a valved spacer device. The measured variables were: basal and post bronchodilator FEV1/FVC, FEV1, FVC, FEF $25-75 \%$, and change of FEV1 and FVC measured in percentage and $\mathrm{ml}$. The statistical analysis was made using the SPSS software, version 23 .

\section{Results}

The characteristics of the selected patients, regarding their sex, age, time passed since the tuberculosis episode, body mass index (BMI), and the results of the basal and post bronchodilator pulmonary

Table I Results basal and post bronchodilator of the spirometric volumes

\begin{tabular}{|c|c|c|c|c|c|c|c|c|c|c|}
\hline \multicolumn{8}{|c|}{ Basal values } & \multicolumn{3}{|c|}{ Post bronchodilator values } \\
\hline $\mathbf{N}$ & Sex & Age & Years TB & BMI & FEVI* & FVC * & FEVI/FVC* & FEVI * & FVC* & FEVI/FVC* \\
\hline I & $\mathrm{F}$ & 61 & 42 & 26.2 & 93 & 104 & 73.9 & 96 & 100 & 78.7 \\
\hline 2 & $\mathrm{~F}$ & 83 & 62 & 25.8 & 50 & 54 & 62.1 & 56 & 71 & 53 \\
\hline 3 & $\mathrm{~F}$ & 69 & 47 & 32 & 53 & 63 & 67.6 & 58 & 61 & 75.9 \\
\hline 4 & $\mathrm{~F}$ & 79 & 53 & 26.2 & 62 & 81 & 57.4 & 72 & 88 & 61 \\
\hline 5 & $\mathrm{~F}$ & 63 & 15 & 25.3 & 56 & 81 & 56.9 & 60 & 85 & 58 \\
\hline 6 & $M$ & 78 & 53 & 20.7 & 49 & 50 & 752 & 52 & 61 & 65.2 \\
\hline 7 & $M$ & 82 & 68 & 22 & 123 & 155 & 60.3 & 130 & 157 & 63.4 \\
\hline 8 & $\mathrm{~F}$ & 85 & 61 & 25.7 & 54 & 73 & 53.6 & 54 & 72 & 54.7 \\
\hline 9 & $\mathrm{~F}$ & 68 & 46 & 26.7 & 42 & 62 & 54.8 & 50 & 75 & 54 \\
\hline 10 & $\mathrm{~F}$ & 71 & 55 & 30.2 & 46 & 59 & 64.5 & 49 & 64 & 63.6 \\
\hline II & $M$ & 83 & 50 & 22.9 & 76 & 114 & 51.2 & 79 & 109 & 55.8 \\
\hline 12 & $M$ & 76 & 16 & 26.3 & 45 & 65 & 54.4 & 53 & 69 & 60 \\
\hline 13 & $\mathrm{~F}$ & 70 & 34 & 16 & 39 & 54 & 60 & 50 & 65 & 64.1 \\
\hline 14 & $M$ & 76 & 59 & 25.9 & 68 & 89 & 59.3 & 75 & 98 & 59.2 \\
\hline 15 & $\mathrm{~F}$ & 68 & 30 & 32 & 103 & 96 & 87.2 & 114 & 101 & 90.9 \\
\hline 16 & $\mathrm{~F}$ & 71 & 34 & 32.5 & 75 & 76 & 80 & 78 & 78 & 81.9 \\
\hline 17 & $\mathrm{~F}$ & 55 & 18 & 32.1 & 61 & 79 & 63.5 & 88 & 88 & 61.3 \\
\hline
\end{tabular}

Years TB, years passed since the tuberculosis episode; BM I, body mass index; FEVI, forced expiratory volume in one second; FVC, forced vital capacity; FEVI/ FVC, forced expiratory volume in one second/forced vital capacity ratio; * percentage of the predicted value

Table 2 Results spirometric pattern

\begin{tabular}{ll}
\hline Spirometric pattern & $\mathbf{N}=\mathbf{I 7}$ \\
\hline Obstructive with normal FVC & 7 \\
Obstructive with low FVC & 6 \\
Normal & 3 \\
Restrictive & $\mathrm{I}$ \\
\hline
\end{tabular}

FVC, forced vital capacity

\section{Discussion}

Our results were compared to 3 of the few existent research in this topic, in which said results match with the previously published information. Lee et al., ${ }^{14}$ South Korea, recruited 21 patients with CAO-PTB and compared them with patients COPD. All the patients had an obstructive spirometric pattern and diminished FVC. ${ }^{14}$ Jiménez et al., ${ }^{6}$ Chile, recruited 25 patients with CAO-PTB, all of them with an obstructive spirometric pattern, specifically 20 with diminished FVC function, are summarized in Table 1 of the 17 evaluated patients, 13 showed an obstructive spirometric pattern $(76 \cdot 5 \%), 3$ a normal spirometric pattern $(17 \cdot 6 \%)$ and 1 a restrictive spirometric pattern $(5 \cdot 9 \%)$. Of the 13 patients with obstructive spirometric pattern, 7 had normal FVC $(53 \cdot 9 \%)$, and 6 diminished FVC (46•1\%) (Table 2). Regarding the changes post bronchodilator, 6 patients had significant changes $(35 \cdot 3 \%)$, which were all obstructive, and 11 patients had no significant changes $(64 \cdot 7 \%)$, being 7 obstructive, 3 normal, and 1 restrictive. A change was considered significant when the difference between the basal and post bronchodilator in FEV1 or FVC was higher than $12 \%$ and $200 \mathrm{ml}$. The difference post bronchodilator in FEV1 and FVC, in percentage and $\mathrm{ml}$, can be seen in Table 3. 
was not included in our study objectives. Considering the findings, we leave the door open for future research about why some patients with pulmonary tuberculosis sequelae would revert post bronchodilator. Maybe they had a bronchial asthma besides the CAO-PTB diagnostic.

Table 3 Post bronchodilator changes of the FEVI and FVC
In fact, Ancic, in 1985, in Chile, assessed the bronchial hyperactivity in 19 patients with pulmonary tuberculosis sequelae through the bronchial incitement using histamine, where 9 resulted positive. ${ }^{18}$

\begin{tabular}{|c|c|c|c|c|c|c|}
\hline $\mathbf{N}$ & Sex & Age & FEVI chg (\%) & FEVI chg (ml) & FVC chg (\%) & FVC chg (ml) \\
\hline I & $\mathrm{F}$ & 61 & 3 & 50 & -4 & -90 \\
\hline 2 & $\mathrm{~F}$ & 83 & II & 100 & 31 & 430 \\
\hline 3 & $\mathrm{~F}$ & 69 & 10 & 100 & -2 & -30 \\
\hline 4 & $\mathrm{~F}$ & 79 & 16 & 210 & 9 & 170 \\
\hline 5 & $\mathrm{~F}$ & 63 & 7 & 80 & 5 & 100 \\
\hline 6 & $M$ & 78 & 5 & 40 & 10 & 190 \\
\hline 7 & $M$ & 82 & 6 & 150 & I & 30 \\
\hline 8 & $\mathrm{~F}$ & 85 & 0 & 0 & -2 & -30 \\
\hline 9 & $\mathrm{~F}$ & 68 & 19 & 150 & 21 & 300 \\
\hline 10 & $\mathrm{~F}$ & 71 & 8 & 70 & 9 & 130 \\
\hline II & $M$ & 83 & 4 & 70 & -4 & 140 \\
\hline 12 & $M$ & 76 & 18 & 210 & 7 & 150 \\
\hline 13 & $\mathrm{~F}$ & 70 & 28 & 220 & 20 & 260 \\
\hline 14 & $M$ & 76 & 10 & 170 & 10 & 290 \\
\hline 15 & $\mathrm{~F}$ & 68 & II & 200 & 6 & 130 \\
\hline 16 & $\mathrm{~F}$ & 71 & 4 & 60 & 2 & 30 \\
\hline 17 & $\mathrm{~F}$ & 55 & 8 & 110 & 12 & 26 \\
\hline
\end{tabular}

FEVI chg (\%), change of the forced expiratory volume in one second in percentage; FEVI chg (ml), change of the forced expiratory volume in one second in milliliters; FVC chg (\%), change of the forced vital capacity in percentage; FVC chg (ml), change of the forced vital capacity in milliliters

In synthesis, we recognize the limits of our study, such as the small sample, and the minor quantity of studies made globally to compare ours with. Since pulmonary tuberculosis is not a considerable health problem in developed countries due to its low prevalence, these countries do not research it. Even so, we can conclude that, in theory, this group of patients has a restrictive component due to the fibrous apical lesion of the pathogen agent (Mycobacterium Tuberculosis), and an obstructive component given by the hyperinflation of the remaining healthy pulmonary parenchyma, and it is similar to the behavior in patients with COPD (6). This follows what Radovic et al. ${ }^{19}$ noted in 2016, in Serbia (Republic of Serbia), where it is mentioned that during the treatment phase of an active pulmonary tuberculosis, the pulmonary function is usually restrictive, which may become obstructive with the years, transforming in what we now know as CAO-PTB, or as a late manifestation of underlying COPD. ${ }^{19}$ We think that the restrictive component explains the decrease in the FCV, and the obstructive component the decrease in FEV1/FVC and FEV1. Nevertheless, we also know that we found some obstructive patients with normal FVC, which could be explained assuming the initial restrictive lesion produced by the tuberculosis was completely compensated with the hyperinflation of the remaining healthy pulmonary parenchyma, thus not being reflected in the spirometry years later, compensating in this way the loss of pulmonary volume. ${ }^{20}$ In any case, in order to clarify this disjunctive, including a Plethysmography in future studies would be convenient, in order to evaluate in an enhanced fashion the pulmonary volumes and objectify the degree of obstruction and restriction in these patients. Including de radiographic analysis of each subject would also be beneficial, for establishing a relation respecting the zone and extension of the pulmonary damage. We insist in suggesting future research on this topic, to even create a more specific guide to treat these patients, for there is no formal literature on the topic nowadays, and many of these patients are treated as COPD or asthmatics.

We deem important and convenient to treat the obstruction of these patients, which can be done through bronchodilators and pulmonary rehabilitation. We also can conclude that the degree of the ventilatory limitation has no relation with age nor amount of years passed after the PTB episode (6). This, because we found different degrees of spirometric limitation in either group of subjects: the ones who had the PTB many years ago and the ones who had it recently.

\section{Conclusion}

Finally, the importance of this research resides in the bibliographic contribution referring to the pulmonary function of patients with CAO-PTB, where we concluded and coincided with other researches, in that the predominant spirometric pattern of these patients would be the obstructive with no significant changes post bronchodilator, with some degree of controversy in the decrease or normality of the FVC, but similar to the pulmonary function in patients with COPD. 


\section{Author contributions}

All authors were involved in the design of this study and the interpretation of study results, contributed to the manuscript from the outset, and read and approved the final draft. All authors vouch for the accuracy of the content included in the final manuscript.

\section{Support statement}

None.

\section{Acknowledgments}

None.

\section{Conflicts of interest}

The authors declare no conflict of interest.

\section{References}

1. Joshi JM. Chronic obstructive pulmonary disease: Knowing what we mean, meaning what we say. Indian $J$ Chest Dis Allied Sci. 2008;50(1):89-96.

2. Dheda $\mathrm{K}$, Booth $\mathrm{H}$, Huggett $\mathrm{JH}$, et al. Lung remodeling in pulmonary tuberculosis. J Infect Dis. 2005;192:1201-1210.

3. Willcox PA, Ferguson AD. Chronic obstructive airways disease following treated pulmonary tuberculosis. Respir Med. 1989;83: 195198.

4. Hnizdo E, Singh T, Churchyard G. Chronic pulmonary function impairment caused by initial and recurrent pulmonary tuberculosis following treatment. Thorax. 2000;55:32-38.

5. Plit ML, Anderson R, Van Rensburg CEJ, et al. Influence of antimicrobial chemotherapy on spirometric parameters and pro-inflamatory indices in severe pulmonary tuberculosis. Eur Respir J. 1998;12:351-356.

6. Jiménez P, Torres V, Lehmann FP, et al. Limitación crónica al flujo aéreo en pacientes con secuelas de tuberculosis pulmonar. Caracterización y comparación con EPOC. Rev Chil Enf Respir. 2006;22:98-104.

7. Gutiérrez M, Beroiza T, Borzone G. Espirometria: Manual de procedimientos. Sociedad chilena de enfermedades respiratorias, 2006. Rev Chil Enf Respir. 2007;23:31-42.
8. Gutiérrez M, Beroiza T, Borzone G. Espirometria: manual de procedimientos. SER Chile. Rev Chil Enferm Respir. 2018;34: 171188.

9. Moore VC. Spirometry: step by step. Breathe. 2012;8:232-240.

10. Miller M R, Hankinson J, Brusaco V. Series ATS/ERS task force: standardization of lung function testing. Standardisation of spirometry. Eur Respir J. 2005;26:319-338.

11. Vandevoorde J, Verbanck S, Schuermans D, et al. Obstructive and restrictive spirometric patterns: fixed cut.offs for FEV1/FEV6 and FEV6. Eur Respir J. 2006;27(2):378-383.

12. Eaton T, Withy S, Garrett JE, et al. Spirometry in primary care practice: The importance of quality assurance and the impact of spirometry workshops. Chest. 1999;116(2):416-423.

13. Masa J F, González M T, Pereira R. Validity of spirometry performed online. Eur Respir J. 2011;37:911-918.

14. Lee JH, Chang JH. Lung function in patients with chronic airflow obstruction due to tuberculosis destroyed lung. Respiratory Medicine. 2003;97:1237-1242.

15. Llanos-Tejada F. Alteraciones espirométricas en pacientes con secuela de tuberculosis pulmonar. Rev Med Hered. 2010;21:77-83.

16. Pauwels RA, Buist AS, Calverley PM, et al. The Gold Scientific Committee (2006). Global strategy for the diagnosis, management, and prevention of chronic obstructive pulmonary disease. Am J Respir Crit Care Med. 2006;163:1256-1276.

17. Solís R, Orihuela D, Carazas E. Respuesta a broncodilatadores en pacientes con lesiones secuelares posttuberculosas. Revista de la Sociedad Peruana de Neumología. 2005;49:25-29.

18. Ancic P, Rioseco P, Méndez E. Hiperreactividad bronquial inespecífica en tuberculosis pulmonar inactiva. Rev Med Chile. 1985; 113:287-290.

19. Radovic M, Ristic L, Ciric Z. Changes in respiratory function impairment following the treatment of severe pulmonary tuberculosis limitations for the underlying COPD detection. International Journal of COPD. 2016;11:1307-1316.

20. Farga V, Rodríguez J. Tuberculosis Latente. Rev Chil Enf Respir. 2012;28:61-68. 